\title{
O MOBILIÁRIO DE ANNA MARIA NIEMEYER PARA O PALÁCIO DA ALVORADA
}

\section{The modern and historic furniture design by Anna Maria Niemeyer for the Alvorada Palace}

Fernanda Freitas Costa de Torres, Instituto Federal de Brasília.

fernanda.torres@ifb.edu.br

Frederico Hudson Ferreira, Instituto Federal de Brasília.

frederico.ferreira@ifb.edu.br

\begin{abstract}
Resumo
Neste artigo é apresentado um recorte da pesquisa realizada durante o pós-doutoramento da autora pela Universidade Federal de Brasília, no Programa de Pós-Graduação em Design, em que ela buscou a recuperação histórica do acervo de mobiliário moderno e histórico do Palácio da Alvorada nas décadas de 1950 e 1960, por ocasião da construção de Brasília. Seu objetivo consistiu no resgate dos desenhos originais e na identificação e investigação do mobiliário moderno em situação de uso ou em depósitos, objetos esses documentos portadores de valores culturais e históricos. Trata-se de um estudo de caso exploratório e descritivo, que teve como foco principal a identificação histórica do acervo do mobiliário moderno projetado por Anna Maria Niemeyer para o Palácio supracitado, em busca de contribuir com a preservação da memória de mobiliário projetado por ela nas décadas de 1950 e 1960. Para isso, procedeu-se à análise visual dos bens móveis em visitas in loco, de documentos, registros e inventários em arquivos públicos, revistas de época e em pesquisa de autoria e estilo do mobiliário. A pesquisa revelou a importantíssima participação de Anna Maria Niemeyer no desenvolvimento de um riquíssimo e numeroso acervo de mobiliário moderno, peças originais de época e de produção exclusiva para ambientação do Palácio da Alvorada, em Brasília. Peças essas com inestimável valor para a história do design do mobiliário moderno brasileiro.
\end{abstract}

Palavras-chave: Anna Maria Niemeyer, Palácio Alvorada, Mobiliário Moderno.

\begin{abstract}
This paper presents an excerpt of a study carried out during the author's post-doctorate at the Federal University of Brasilia, in the Postgraduate Program in Design, in which she sought the historical recovery of the collection of the modern and historic furniture at the Alvorada Palace in the 1950s and 1960s, when Brasilia was built. Its objective was to recover the original drawings and to identify and investigate the modern furniture in use or in the deposits, which are objects that carry cultural and historical values. This is an exploratory and descriptive case study, whose main focus was the historical identification of the collection of modern furniture designed by Anna Maria Niemeyer for the aforementioned Palace, in search of contributing to the preservation of the furniture memory she designed in the 1950s and 1960s. For this purpose, a visual analysis was carried out on in loco visits of documents, records and inventories in public archives, magazines of the period and in research on authorship and style of furniture. The research revealed the very important participation of Anna Maria Niemeyer in the development of a very rich and numerous collection of modern furniture, original pieces of the period and exclusive production for ambiance at the Alvorada Palace in Brasilia. These pieces are priceless for the history of modern Brazilian furniture design.
\end{abstract}

Keywords: Anna Maria Niemeyer, Alvorada Palace, Modern Furniture. 


\section{Introdução}

De acordo com Santos (2015), a década de 1930 representou um momento de virada para o programa modernista do mobiliário. A década de 1950 mostrou-se um momento político e economicamente bastante favorável às iniciativas ligadas à produção industrial. E a construção de Brasília consistiu em importantes incentivos para a validação e consolidação da arquitetura moderna, bem como para o desenvolvimento do desenho industrial. A chancela definitiva para o movimento moderno na arquitetura e no design talvez tenha sido o convite a diversos designers para projetarem os mobiliários e a ambientação de interiores dos arrojados edifícios administrativos da nova capital.

O convite para projetar a ambientação de interiores e mobiliário que representassem o Brasil, foi feito a grandes arquitetos/designers para a decoração dos Palácios da Alvorada e do Planalto. Nos imensos salões e mezaninos desses monumentos é possível encontrar móveis de Joaquim Tenreiro, Jorge Zalszupin, Sérgio Rodrigues, Anna Maria Niemeyer e Oscar Niemeyer, entre outros (COSTA, 2014). Para a execução dos projetos de interiores de Brasília, Oscar Niemeyer convocou artistas plásticos - Di Cavalcanti, Athos Bulcão, Saldanha e Ceschiatti -, e sua filha Anna Maria Niemeyer passou a cuidar do mobiliário (NIEMEYER, 1996).

Anna Maria de Niemeyer Soares nasceu no dia 16 de dezembro no Rio de Janeiro, mãe de cinco filhos, desde muito nova trabalhou com o pai, o arquiteto Oscar Niemeyer. Quando da construção de Brasília, foi responsável pelos desenhos e produção dos mobiliários, e da decoração que viria a ser utilizada nos Palácios da Alvorada e do Planalto, dentre outros prédios públicos da então embrionária Capital Federal. A partir de 1957, ainda no Rio de Janeiro, contratada pela Companhia Urbanizadora da Nova Capital do Brasil (NOVACAP), começou a trabalhar nos projetos de Brasília, que começaram a ser feitos em planta. Foi responsável pela decoração do Palácio da Alvorada, Supremo Tribunal, Palácio do Planalto, Congresso Nacional, onde foi feita uma pesquisa do que era necessário junto às autoridades que viriam a ocupar os gabinetes e desta forma iniciou o desenvolvimento dos projetos e os desenhos dos móveis. Contando com algumas dicas de Dona Sarah Kubitschek, recebeu carta branca para a decoração no Palácio da Alvorada, onde Anna realmente escolheu absolutamente tudo, inclusive roupa de cama, talheres, louça, toalhas de mesa, que eram enormes e tinham que ser encomendadas. Anna cuidou pessoalmente disso tudo, já nos outros Palácios sua marca não foi tão forte, porque o Palácio da Alvorada, diferentemente dos outros, era uma casa, precisava desse cuidado a mais. Nos outros não, só a parte de mobiliário, cortinas e tapetes (SOARES, 1989).

No grupo dos principais designers de mobiliário e artistas plásticos responsáveis pela ambientação dos Palácios para a inauguração de Brasília destaca-se a importância da presença de Anna Maria Niemeyer, bem como os seus projetos de mobiliário desenvolvidos na década de 1960, os quais são pouco citados e lembrados na literatura especializada. Quando citada, Anna Maria Niemeyer é reverenciada pelos desenhos de mobiliários que idealizou com o seu pai a partir da década de 1970. Como cita Andrade (2017), no diagrama dos designers nacionais, onde traz somente as peças de mobiliário da participação de Anna Maria Niemeyer em parceria com Oscar Niemeyer, com destaque para a Poltrona Alta (1971) e a Poltrona Rio (1977). 
Segundo Soares (1989), Anna Maria Niemeyer fala em seu depoimento sobre a influência do pai, Oscar Niemeyer, no seu trabalho:

Olha, eu sempre trabalhei com ele, desde menina. E apesar de eu não ter feito arquitetura, eu trabalhava em desenho no escritório, mais especialmente com mobiliário. E todos os projetos dele, eu fazia vamos dizer, a ambientação, a parte de móveis, cortina, essas coisas, decoração, ele não gosta desse nome, mas no fim é decoração. E assim, eu comecei a trabalhar para a NOVACAP em 1957, já nos projetos de Brasília e que começava a ser feito aqui no Rio, em planta Palácio da Alvorada, Supremo Tribunal, Palácio do Planalto, Congresso Nacional, foi feito uma pesquisa do que era necessário; quer dizer, já tinha contato com as autoridades todas e comecei a fazer o projeto, os desenhos dos móveis. A NOVACAP fazia concorrência entre as firmas e eu fiscalizava nas fábricas, aqui no rio, de vez em quando eu ia a Brasília, Brasília não tinha nessa ocasião.

Segundo Tavares (2014), o mobiliário da nova capital foi desenhado, quase todo, por Anna Maria Niemeyer, praticamente a única mulher que se dispôs a enfrentar a poeira da cidade em construção. Ela atuou como Técnica de Decoração do Departamento de Urbanismo e Arquitetura (DUA) e da NOVACAP, no período de 1957 até 1973, e foi responsável pelo projeto de interiores e de mobiliário, bem como por toda a ambientação interna do Palácio da Alvorada, arrumou tudo de uma forma estética delicada e simples, visando sempre manter a harmonia com a arquitetura das construções (SOARES, 1989).

Na NOVACAP, Anna Maria Niemeyer preparava os desenhos dos móveis e encaminhava ao setor responsável, que fazia a licitação entre as firmas concorrentes. Ela fiscalizava a produção nas fábricas. Entre as empresas citadas por Anna estão aquelas fora da capital, como Leandro Martins, Teperman, Liceu de Artes e Ofícios de São Paulo, e a loja Mainline, de Brasília. Devido à necessidade de agilidade na produção das peças, muitas sequer passaram pelo processo de prototipagem, etapa comum no desenvolvimento de móveis, saindo direto da prancheta para a linha de produção; às vezes, pequenas modificações no projeto eram realizadas diretamente na fábrica.

Segundo Soares (1989) Anna relata em seu depoimento que:

Trabalhava-se muito, noite adentro, e era engraçado quando aqueles móveis chegaram. Aquele pessoal, aqueles candangos não sabiam, você pedia pra eles abrirem um sofá, eles encostavam ao contrário assim na parede. Uma vez eu cheguei no Palácio da Alvorada com o Ítalo Campofiorito, tarde, devia ser uma hora da manhã, nós íamos arrumar os móveis que tinham chegado, que tinha ficado tudo pronto pro dia. E o elevador ainda não tinha porta, enguiçou, ficou parado assim entre dois andares, e tinha assim uns operários, e eu comecei a ficar nervosa, pedindo pra eles chamarem o engenheiro, eles riam loucamente, e eu disse: "Mas por que que vocês estão rindo em vez de acudir a gente?" Aí ele me disse: "Ah dona, gaiola mais engraçada essa, que pega três de uma vez só." Que era eu, Ítalo e tinha mais alguém. Mas eu gostei muito de Brasília. Foi uma época muito boa da minha vida, muito boa porque a gente trabalhava... em primeiro lugar, animados. Eu desenhava todos os móveis. De todos os prédios. Uns poucos foram adquiridos prontos, a maior parte eu desenhei.

Segundo a Revista Módulo (1959), a orientação adotada para a decoração do Palácio da Alvorada foi de interiores sóbrios e simples, em harmonia com a arquitetura da obra. Anna Maria Niemeyer explica o conceito adotado e aprofundado: 
Minha intenção, estudando o mobiliário do Palácio da Alvorada, foi principalmente harmonizá-lo com a arquitetura. Algumas peças - as mais simples e modestas - obedeceram a desenhos especiais, sendo, porém a maioria escolhida entre elementos já clássicos do mobiliário contemporâneo. Acrescentei ao conjunto alguns exemplos do mobiliário colonial - não tantos nem tão ricos como desejava - procurando com isso dar-lhe um certo caráter de coisa nossa, brasileira.

Esse mobiliário foi desenvolvido com características brasileiras, buscando harmonizá-lo com o material utilizado na arquitetura do Palácio da Alvorada, ou seja, panos de vidro estruturados em alumínio anodizado e vedados com vidro liso translúcido, pintura lisa e mármore branco Espírito Santo com acabamento polido. Nos interiores, foram aplicados diferentes tipos de madeira, granito e mármores diversos, vários tipos de cerâmica, porcelanato, carpete, revestimento vinílico ou melamínico, latão polido, espelho, papel de parede, lambri, pintura lisa, pastilha de cerâmica e outros. Na confecção dos móveis foram utilizadas matérias-primas nacionais, como a madeira do jacarandá, protagonista na produção dos móveis modernos do País.

Os mobiliários criados e produzidos por ocasião da construção de Brasília são objetos e, ao mesmo tempo, documentos, considerados patrimônio cultural brasileiro. Esses mobiliários/objetos/documentos são dotados de uma significação especial e portadores de sentidos e memórias.

O mobiliário moderno original de Brasília carrega as funções simbólica e cultural, e o seu valor de uso, pois estão em plena utilização nos interiores dos Palácios há 60 anos e presentes em decisões presidenciais importantes para a nossa história.

Na busca de difundir a valorização do design do mobiliário moderno desenvolvido por ocasião da construção de Brasília, como documento portador de sentido e valor histórico- cultural, nesta pesquisa a intenção foi contribuir para o fortalecimento da cultura brasileira e da memória do mobiliário projetado por Anna Maria Niemeyer, nas décadas de 1950 e 1960, tendo como foco principal a identificação histórica do acervo do mobiliário moderno projetado por Anna para o Palácio da Alvorada. Objetivou também atualizar a catalogação, o registro de patrimônio e a identificação de autoria, assim como resgatar os desenhos originais e as fotografias. Esses documentos guardam informações, significados, mensagens e registros e possuem importância fundamental para o desenvolvimento e enriquecimento da cultura brasileira, além de proporcionar o diálogo entre o acervo e o observador externo, contribuindo para a sua preservação e recuperação para o futuro.

\section{Metodologia}

Este trabalho se caracteriza como um estudo exploratório, com pesquisa de informações ainda pouco investigadas e realizadas no segmento da identificação histórica, da preservação e da conservação, por meio de estudo de caso descritivo (GIL, 2002).

\section{Local e desenvolvimento do trabalho}


A pesquisa foi desenvolvida no Programa de Pós-Graduação em Design da Universidade de Brasília, com apoio da Coordenação de Aperfeiçoamento de Pessoal de Nível Superior (CAPES), em conjunto com a Coordenação de Patrimônio da Presidência da República. Nesses setores ocorreram visitas semanais para estudo do mobiliário armazenado no depósito da Presidência da República do Brasil, visitas ao acervo do Arquivo Público do Distrito Federal e do Núcleo de Pesquisa, Conservação e Restauro de Mobiliário Moderno do Instituto Federal de Educação, Ciência e Tecnologia de Brasília, para pesquisa documental do Palácio da Alvorada. E, ainda, foi realizada pesquisa em arquivos digitais do Arquivo Nacional e do Instituto do Patrimônio Histórico e Artístico Nacional.

\section{Material e Método}

Segundo Mensch (1987), os objetos produzidos pelo homem são portadores de informações intrínsecas (invariáveis) e extrínsecas (variáveis). As informações intrínsecas são as deduzidas do próprio objeto, através da análise das suas propriedades físicas (descrição física), como: composição material, técnica construtiva e morfologia (forma espacial, dimensões, estrutura da superfície, cor, padrões de cor, imagens, finalidade e tipo de uso). As extrínsecas (informações contextuais/variáveis) são aquelas obtidas de outras fontes que não do objeto. Permitem conhecer os contextos em que os objetos existiram, funcionaram e adquiriram significado. Podem ser fontes bibliográficas e documentais.

Foram pesquisadas as informações intrínsecas e extrínsecas dos mobiliários modernos das décadas de 1950 e 1960, pertencentes ao acervo do Palácio da Alvorada. Para tal, foi utilizado o método do estudo de caso exploratório, por meio de análises de documentos e do mobiliário, em pesquisa de campo.

Nas análises extrínsecas de documentos, pesquisaram-se os desenhos técnicos diversos disponibilizados para consulta pública nos arquivos da NOVACAP; nas publicações da Revista Módulo, volumes de 1956 até 1960; e no Inventário de Bens Arquitetônicos do Palácio da Alvorada de 2007/2008. Também foram feitas pesquisas no Inventário de Bens Culturais da Presidência da República do Palácio da Alvorada e no Depósito de Bens Materiais.

Nas análises intrínsecas de mobiliário no depósito da Presidência da República, as etapas do trabalho foram: análise visual, análise formal, identificação de autoria e estilo e organização dos bens materiais em grupos.

A primeira etapa foi à análise visual por intermédio da triagem de centenas de peças de mobiliário que se encontravam armazenadas em depósito, de forma a manter nesse local somente os bens materiais que apresentem relevante interesse histórico ou artístico. Por meio de inventário descritivo do mobiliário, procedeu-se à realização de identificação das peças de mobiliário moderno, incluindo descrição detalhada, medidas e registro fotográfico.

Na segunda etapa, procedeu-se à análise formal e à autoria do estilo do objeto, mediante a classificação e organização do mobiliário em quatro grupos de interesse previamente definidos:

Grupo 1: mobiliário moderno assinado por designer produzido em pequena escala; 
Grupo 2: mobiliário moderno assinado por designer produzido em série;

Grupo 3: mobiliário antigo; e

Grupo 4: mobiliário relevante com autoria desconhecida.

$\mathrm{Na}$ terceira etapa ocorreu a organização das peças de mobiliário moderno em grupos, através de separação espacial, visando facilitar a identificação desses grupos para encaminhamentos futuros.

Durante as visitas foi realizada não somente a verificação das peças de mobiliário moderno, mas também a triagem, atualização da ficha técnica e do inventário e classificação desses objetos, além das providências para a organização do local.

O recorte desta pesquisa concentrou-se no Grupo 1 - mobiliário moderno assinado por designer e produzido em pequena escala e as peças de autoria de Anna Maria Niemeyer para o Palácio da Alvorada e a Residência Oficial do Presidente da República do Brasil. Neste grupo, a análise extrínseca foi realizada através de estudos dos desenhos técnicos de mobiliários originais, documentos do acervo de plantas baixas do Arquivo Público do Distrito Federal. A identificação de autoria desses documentos foi realizada em 189 peças de mobiliário moderno pertencentes ao acervo do Palácio da Alvorada. Já na análise intrínseca do mobiliário no Depósito da Presidência da República as etapas do trabalho foram: análise visual, análise formal e identificação de autoria. Após essa pesquisa houve o confrontamento dos documentos encontrados com os mobiliários em depósito e inventariados.

Segundo Bueno (2012), o mobiliário brasileiro que surgiu para dialogar com a nossa arquitetura moderna revelou as qualidades estéticas e técnicas, a beleza, a importância do desenho original e o valor da nossa cultura.

\section{Resultados}

Na análise intrínseca de mobiliário no Depósito da Presidência da República, verificou-se que muitas peças de mobiliário moderno do acervo não estavam inventariadas e também muitas outras possuíam a identificação numérica de patrimônio; em relação às suas fichas técnicas de catalogação, não constavam a identificação de autoria do projeto nem o nome da peça e também não havia a data de aquisição e nem o registro do atual estado de conservação.

A ficha técnica de catalogação padrão utilizada pela Coordenação de Patrimônio da Presidência da República durante o inventário segue o modelo do Instituto Brasileiro de Museus, em que a mesma ficha é utilizada para três categorias: obras de arte, tapeçaria e mobiliário em geral.

$\mathrm{Na}$ etapa de identificação de autoria do mobiliário moderno pertencente ao Palácio da Alvorada, encontramos um total de 110 peças assinadas pelos designers: Sérgio Rodrigues, Maurício Azeredo, Vico Magistretti, Le Corbusier, Joaquim Tenreiro, Marcel Breuer, Charles Eames, Geraldo de Barros, Mies Van Der Rohe, Chesterfield, Jacqueline Terpins, Anna Maria 
Niemeyer e seu pai Oscar Niemeyer, Eero Saarinen, Cini Boeri, Fabricio Ballardini e Lúcio Costanzi, Reno Bonzon, Carlos Motta e Jorge Zalszupin.

Entre essas peças, algumas são de autoria desconhecida, enquanto outras foram desenvolvidas pela fábrica Broyhill, exclusivamente durante as décadas de 1960 e 1970. Essa linha de mobiliário, denominada Broyhill Brasília, foi inspirada nas colunas das construções de Oscar Niemeyer, como cadeiras, cômodas, estantes, escrivaninhas, criados-mudos e mesas de diversos tipos. Também, foi observada a predominância de mobiliário de algumas fábricas: Broyhill, Forma, Mainline, Knoll, L’atelier, Herman Miller, Italma e Móveis Celina.

Nesse acervo do Palácio da Alvorada há a presença de um grande acervo de mobiliário moderno projetado por Anna Maria Niemeyer, conforme apresentado no Quadro 1.

- Cama para o apartamento do Presidente.

- Mesa de cabeceira de jacarandá e latão para o apartamento do Presidente

- Mesa de pau-marfim travado de latão e granito verde italiano para o apartamento do Presidente.

- Mesa do gabinete do presidente com base em latão polido e tampo de granito.

- Genuflexório de jacarandá, veludo e palhinha para a Capela de Nossa Senhora da Alvorada.

- Genuflexório de jacarandá e veludo para a Capela de Nossa Senhora da Alvorada.

- Cadeira de jacarandá, veludo e palhinha para a Capela de Nossa Senhora da Alvorada.

- Banco de jacarandá e veludo para a Capela de Nossa Senhora da Alvorada.

- Console de jacarandá para a Capela de Nossa Senhora da Alvorada.

- Mesa de latão e de madeira ebanizada para banquete.

- Cadeira de pau-marfim e palhinha francesa para a saleta de estudos.

- Cadeira de braço de tecido e jacarandá.

- Cadeira de braço de tecido e jacarandá.

- Cadeira de jacarandá e de tecido para o salão de banquete.

- Camas para dormitórios.

- Sofás de tecido.

- Mesa de jacarandá e latão para banquete.

- Mesa de canto de latão polido e de granito ouro velho.

- Mesa de canto de latão polido e mármore.

- Mesa de canto baixa de jacarandá.

- Mesa de latão e granito preto.

- Mesa lateral de jacarandá e vidro.

- Escrivaninha de jacarandá e latão.

- Poltronas em madeira de jacarandá (diversos modelos).

- Aparador de pau-marfim e mármore com uma gaveta. 
- Mesa lateral de madeira de jacarandá e vidro.

- Mesa de centro de madeira e vidro.

- Mesa de latão e de madeira ebanizada para banquete.

- Marquesa de compensado ebanizado e palhinha indiana.

No Quadro 1 são apresentadas as peças de mobiliário moderno atribuídas a Anna Maria Niemeyer, muitas únicas e exclusivas, com materiais e técnicas que resultam em similaridade estético-formal. São diversas as categorias de mobiliário, como cadeiras, poltronas, sofás, mesas para funções diversas e combinações de uso de materiais como madeira, vidro, mármore, granito, latão dourado, alumínio anodizado, couro, veludo e palhinha. Entre as madeiras mais presentes nos móveis modernos de Anna Maria Niemeyer estão a peroba-do-campo, o pau- marfim e, predominantemente, o jacarandá.

Nesse cenário, todos os móveis suscitam leveza e parecem levantar do chão, o que reforça duas características marcantes no design de Anna Maria Niemeyer para o Palácio da Alvorada, sendo a primeira a presença de pés de latão dourado nas mesas de jantar, lateral, de centro e de trabalho, assim como em sofás e aparadores, como apresenta a Figura 1, uma mesa de trabalho de 1961 que possui seis gavetas em estilo modernista, com tampo retangular unido por colunas de metal cromado, com quatro pés tubulares. Essa peça foi encontrada no depósito e também em uso no escritório.

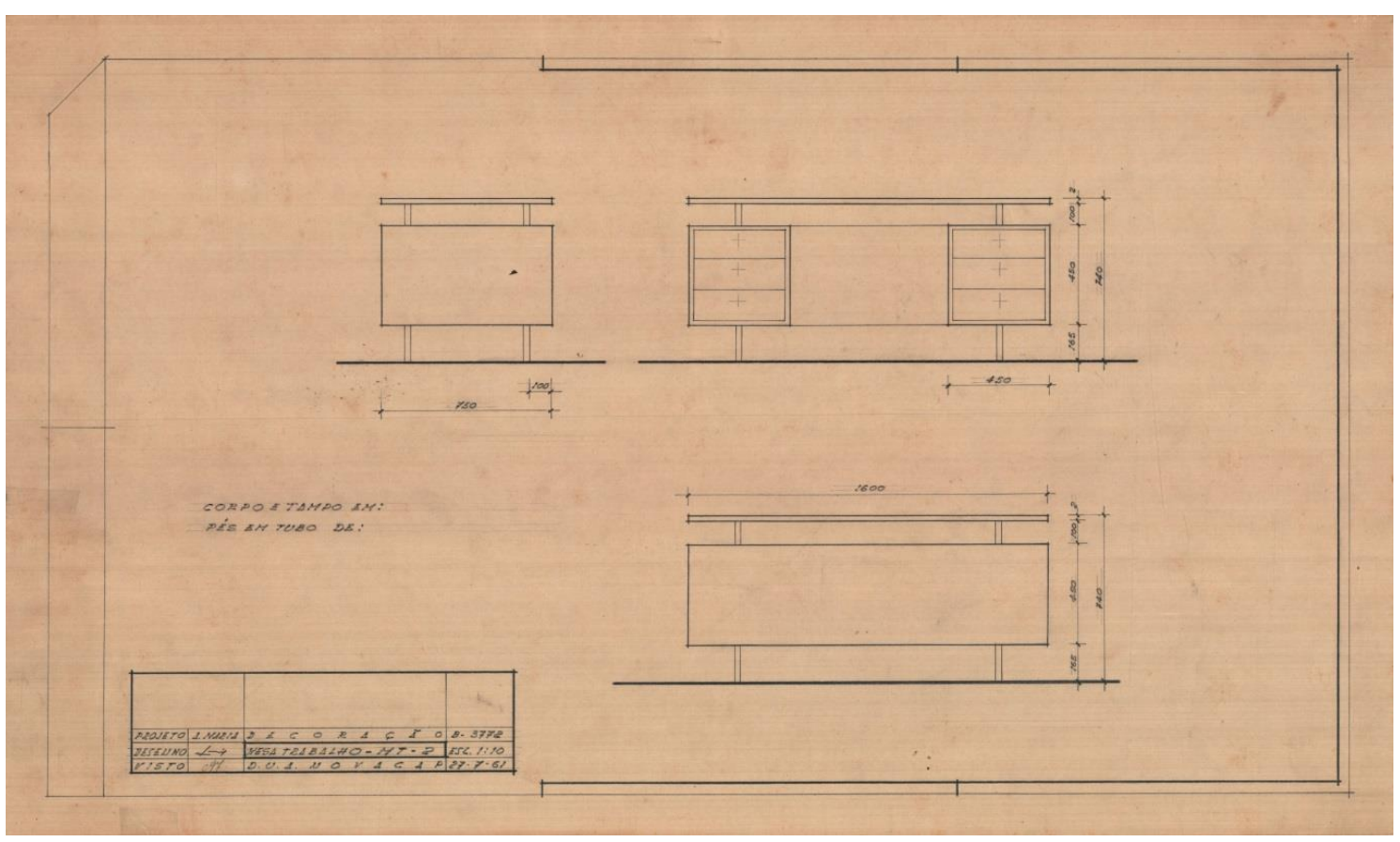

Figura 1: Projeto mesa de trabalho por Anna Maria Niemeyer.

Fonte: Plantas do Arquivo Público do Distrito Federal e Acervo da autora deste artigo.

A segunda característica do design de Anna Maria Niemeyer é o uso da madeira maciça de jacarandá encerado e torneado, no projeto de cadeiras, mesas e no mobiliário para a Capela de Nossa Senhora da Alvorada. 
Durante a pesquisa algumas peças de mobiliário moderno desenhadas por Anna Maria Niemeyer havia o registro fotográfico de alguns dos projetos de interiores do Palácio da Alvorada também desenvolvidos por Anna, na época da inauguração desse monumento. São eles: a Suíte Presidencial, o Salão de Banquetes, o Salão Nobre e a Capela de Nossa Senhora da Alvorada. Na Suíte Presidencial havia o registro do projeto, da cama e de mesa de cabeceira, a qual já fez parte da ambientação da Suíte Presidencial em 1961, conforme fotografia de época (Figura 2), feita em jacarandá, com uma gaveta, estilo modernista, tampa retangular e trava entre os pés de latão dourado.

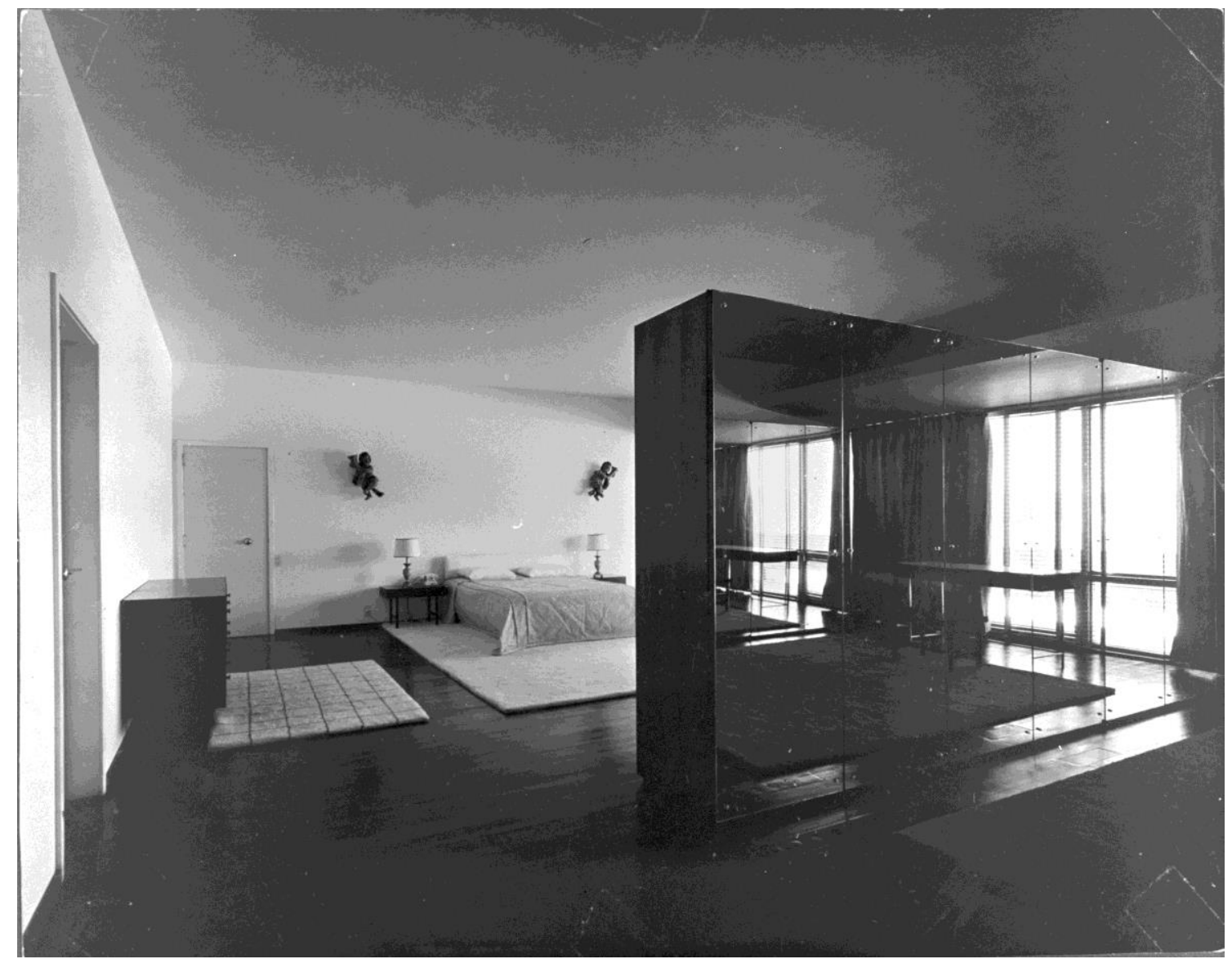

Figura 2: Suíte Presidencial com mesa de cabeceira projetada por Anna Maria Niemeyer

Fonte: Arquivo digital Instituto do Patrimônio Histórico e Artístico Nacional

Duas mesas de cabeceira originais passaram pelo processo de restauro no ano 2018 na Oficina Escola de Restauro de Mobiliário Moderno do Instituto Federal de Brasília, pois o estado de conservação das mesmas era ruim, com arranhões no tampo, perda do laminado nas partes inferiores e ausência da travessa lateral e do tubo de latão dourado.

Na Figura 3 abaixo apresenta o registro em planta com os desenhos técnicos originais da mesa de cabeceira, e com o visto de Anna Maria Niemeyer, sem data. 


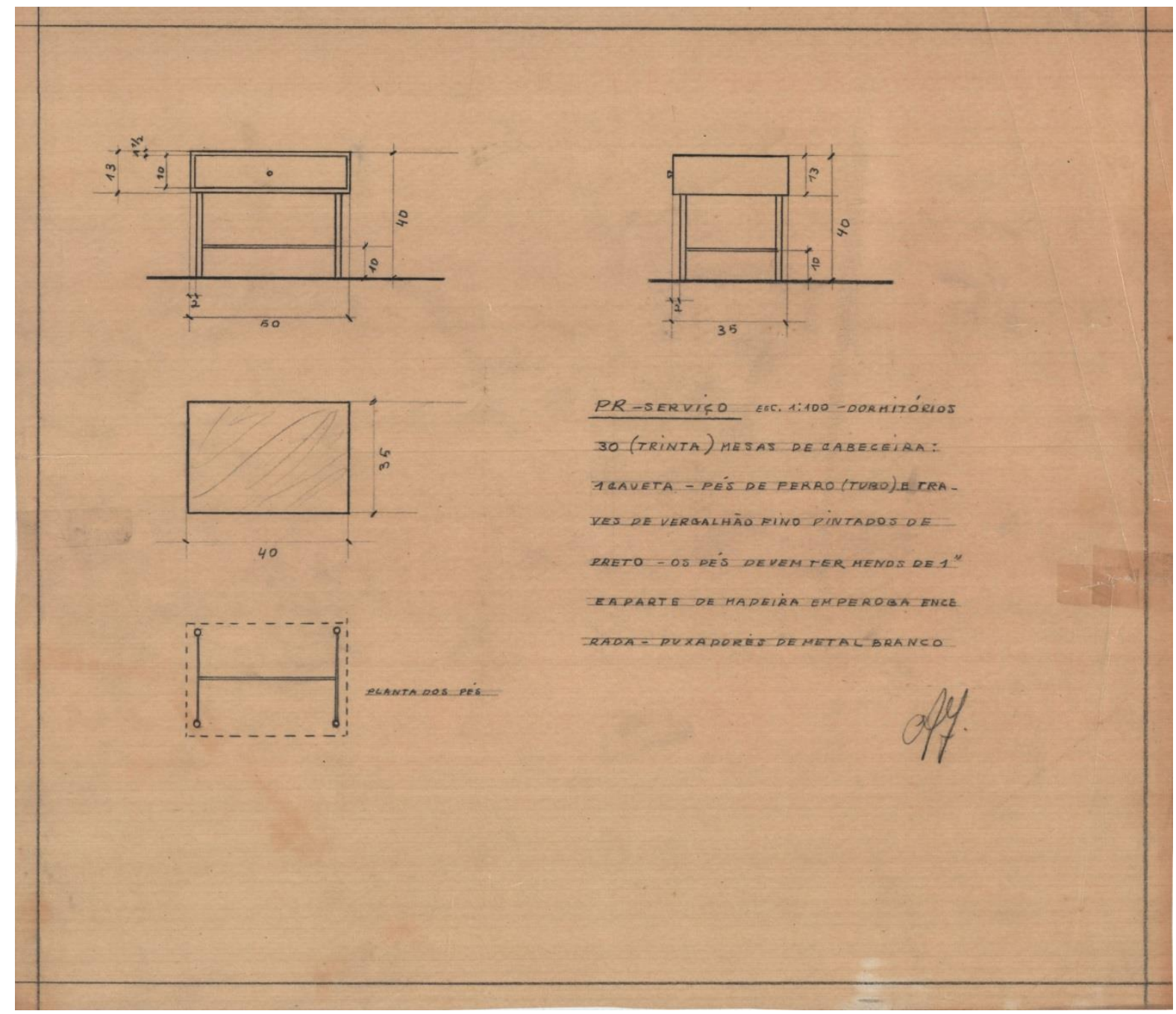

Figura 3: Mesa de cabeceira projetada por Anna Maria Niemeyer

Fonte: Plantas do Arquivo Público do Distrito Federal

$\mathrm{Na}$ análise intrínseca das peças de autoria de Anna Maria Niemeyer para observação, registro e análise, encontrei, por exemplo, a Escrivaninha Presidente, feita de jacarandá e com pés de latão, classificada também como do "Grupo 1 - mobiliário moderno assinado por designer produzido em pequena escala".

$\mathrm{Na}$ análise extrínseca, na pesquisa de autoria do mobiliário, o estudo das plantas com desenhos originais foi realizado a partir de imagens do levantamento iconográfico, dos desenhos técnicos, das anotações e das legendas. Algumas das plantas dos móveis do Palácio da Alvorada pesquisadas possuem somente os desenhos técnicos do mobiliário com uma numeração de folha, mas todos os projetos apresentam a mesma linguagem formal e os mesmos materiais das plantas assinadas por Anna Maria Niemeyer. As plantas encontradas são, em sua maioria, do Departamento de Urbanismo e Arquitetura da NOVACAP. Verifiquei algumas plantas com os desenhos técnicos e a descrição do mobiliário contendo apenas o visto de Anna Maria Niemeyer; em outras plantas, os desenhos técnicos traziam a legenda completa, a data, a autoria do projeto, a autoria do desenho e o visto, todos realizados por Anna Maria Niemeyer, conforme atesta a Figuras 4. 


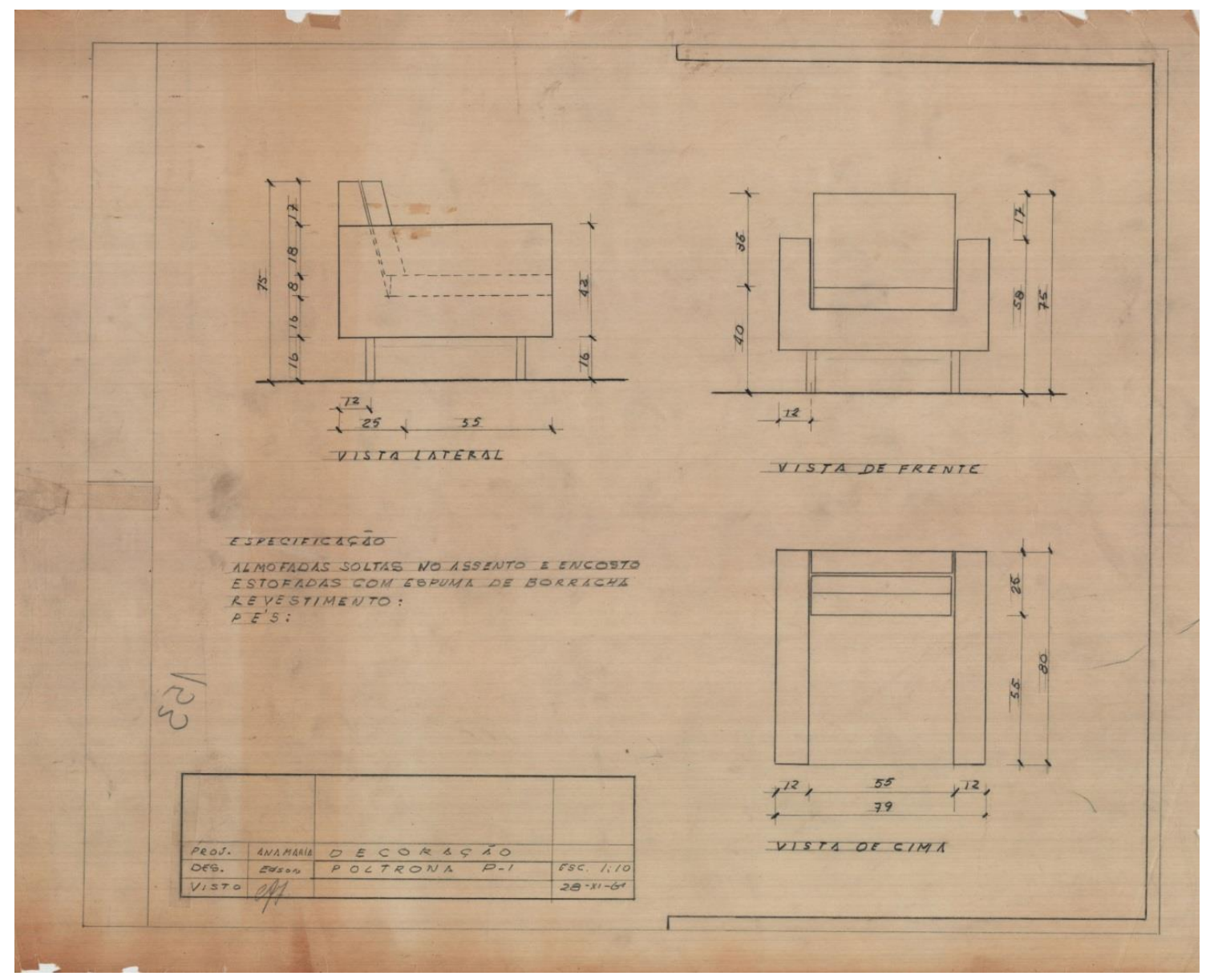

Figura 4: Desenhos originais de poltrona assinado por Anna Maria Niemeyer em 1961

Fonte: Acervo do Arquivo Público do Distrito Federal

Em dezoito peças de mobiliário moderno de autoria de Anna Maria Niemeyer para o Palácio da Alvorada e da Capela de Nossa Senhora da Alvorada não foram localizados os respectivos desenhos técnicos, mas no inventário disponibilizado para pesquisa eles constam como de autoria dessa projetista. Em outras vinte plantas com desenhos originais de mobiliários modernos assinados por Anna não foi possível localizar o respectivo mobiliário.

\section{Conclusão}

No acervo do mobiliário moderno de Brasília das décadas de 1950 e 1960 estudado, muitas peças são originais de época e, em sua grande maioria, de produção exclusiva para a ambientação dos Palácios Presidenciais, no entanto possuem inestimável valor cultural, fazem parte da história da construção da nova capital do Brasil e também da história do design de mobiliário moderno nacional. Por essa razão, tais peças devem ser consideradas Patrimônio Cultural Brasileiro, pois são objetos documentos portadores de informação, assim como os edifícios e as obras de arte da época. É lamentável saber que ainda existe pouco conhecimento, por parte da sociedade e da literatura específica, sobre a origem, a autoria e a 
importância desse extraordinário e riquíssimo acervo histórico-cultural brasileiro.

Esse acervo é um importante legado do design para a cidade de Brasília e necessita de reconhecimento, preservação e conservação. Para que não desapareça, como infelizmente aconteceu com algumas peças no decorrer do tempo e com aqueles móveis que se encontram desconfigurados em depósitos ou acomodados em estado precário de conservação e sem condições de uso ou, mesmo, de exposição, esse mobiliário precisa ser restaurado enquanto ainda é possível.

Na documentação pesquisada e nas fichas técnicas catalográficas existe a necessidade de inclusão de itens próprios para a descrição e classificação do mobiliário moderno, assim como seu estado de conservação do mobiliário detalhado. Ademais, é premente a atualização dos inventários, o que ajudará na disponibilização de informações sobre o estado de conservação das peças e no reconhecimento da autoria do projeto, data de criação e contexto histórico do mobiliário. Isso porque muitas peças se encontram em depósitos, reservas técnicas, ou em escritórios e gabinetes ou em espaços de circulação das visitas guiadas nos prédios públicos de Brasília.

Após a finalização do trabalho de identificação e separação das peças de mobiliário moderno no depósito, recomendo que os móveis do Grupo 1 - “O mobiliário moderno assinado por design produzido em pequena escala" - sejam recuperados e restaurados, pois são de grande relevância para a história do mobiliário moderno da capital do Brasil.

Há também a necessidade de novas pesquisas sobre o rico e numeroso acervo de Anna Maria Niemeyer em Brasília e a importância do seu trabalho na NOVACAP nas décadas de 1950 e 1960. Muitas dessas peças ainda estão em uso nos Palácios da Presidência da República do Brasil e algumas, no mesmo local de origem, outras se encontram em depósito e necessitam de intervenções de um projeto de restauro, enquanto outras tantas estão desaparecidas ou desconfiguradas. Felizmente, no entanto, muitos desses objetos podem ser reconstruídos a partir do desenho original, uma contribuição do design como ferramenta para recuperar nossa história. Nos registros documentais, desenhos técnicos e fotografias, verifiquei o propósito dessa designer em destacar a monumentalidade, transparência e delicadeza da arquitetura com a definição do mobiliário, assim como a grande importância e relevância do acervo dessa mobília em agregar história e brasilidade aos palácios brasilienses.

Ainda paira a necessidade do fortalecimento da consciência de preservação, conservação e memória do mobiliário moderno projetado por Anna Maria Niemeyer exclusivamente para Brasília. Belíssimo trabalho esse que frequentemente é esquecido, ou até ignorado, na literatura, em que muitas vezes Anna é reconhecida somente como coautora ou colaboradora 
dos projetos de mobiliário do seu pai, o arquiteto Oscar Niemeyer, a exemplo da Poltrona Paris de 1970, projetada para o Palácio do Congresso Nacional; e do conjunto Easy Chair (banquete e poltrona alta) de 1971, projetado para o Salão Verde da Câmara dos Deputados, em Brasília.

A atuação de Anna Maria Niemeyer como designer é exemplificadora de projetos de peças únicas e sob encomenda para os Palácios de Brasília, sendo a sua produção de forma artesanal também da produção industrial.

Há um longo percurso para a integração do design com o patrimônio cultural, o que fortalecerá as ações de conservação, preservação e restauro do mobiliário moderno e histórico de Brasília, assim como sua salvaguarda e valorização.

Tal integração também suscitará a necessidade de criação de um Centro de Conservação e Restauro do Mobiliário Moderno de Brasília ou, até mesmo, de um Museu do Mobiliário Moderno, visando difundir o reconhecimento, socialização e compreensão do seu significado, identidade e valor para a história do design brasileiro.

O desenho original de uma mesa de 1960 ou mesmo de um componente dessa mesa, por exemplo, são objetos de patrimônio cultural e podem trazer diversas informações sobre o passado, as técnicas construtivas, os materiais empregados, as técnicas de acabamento e os encaixes; podem também informar sua função de uso, sua ergonomia, medidas utilizadas e, ainda, a função simbólica, por quem foi utilizada e em quais momentos áureos da nossa história.

\section{Agradecimentos}

À Coordenação de Aperfeiçoamento de Pessoal de Nível Superior (CAPES), ao Programa de Pós-Graduação em Design da Universidade de Brasília e à Coordenação de Patrimônio da Presidência da República do Brasil e ao Restauro Núcleo de Pesquisa em Mobiliário Moderno Brasileiro do Instituto Federal de Educação, Ciência e Tecnologia de Brasília, pelo apoio.

\section{Referências}

ANDRADE, M. V. Jorge Zalszupin: contribuições para o design do móvel moderno brasileiro (1959-20018). 2017. Dissertação (Mestrado em Arquitetura e Urbanismo) Faculdade de Arquitetura e Urbanismo da Universidade de São Paulo, Brasília, 2017.

BUENO, G. O auge do processo criativo no período moderno no Brasil. Graça Bueno e os móveis modernos brasileiros. Disponível em: https://casaclaudia.abril.com.br/moveisacessorios/graca-bueno-e-os-moveis-modernos-brasileiros/. Acesso em: 2 jul. 2019. 
COSTA, J. A. Arquitetos - designers: o mobiliário moderno da Universidade de Brasília. 2014. Dissertação (Mestrado em Arquitetura e Urbanismo) - Universidade de Brasília, Brasília, 2014.

Revista Módulo, Decoração do Palácio da Alvorada. Rio de Janeiro, v. 2, n. 12, fev. 1959.

GIL, A. C. Como elaborar projetos de pesquisa. 4. ed. São Paulo: Atlas, 2002.

IPHAN. Acervo digital IPHAN. [S.1.]: IPHAN, 2020. Disponível em: http://acervodigital.iphan.gov.br/xmlui/handle/123456789/6814?discover?rpp=10\&etal=0\&q uery=interiores+pal\%C3\%A1cio+alvorada. Acesso em: 10 jan. 2020.

MENSCH, P. Museus em movimento: uma estimulante visão dinâmica sobre interrelação museologia-museus. Cadernos Museológicos, n. 1, p. 51, 1987.

NIEMEYER, O. O Alvorada. Jornal Correio Braziliense, Brasília, 27 ago. 1996. RYBCZYNSKI, W. Casa: pequena história de uma ideia. Rio de Janeiro: Record, 1996.

SANTOS, M C L dos. Móvel moderno no Brasil. São Paulo: Olhares, 2015.

SOARES, A. M. de N. Depoimento - Programa de História Oral. Brasília: Arquivo Público do Distrito Federal, 1989. 16 p.

TAVARES, F. 1964: o golpe. Porto Alegre: Editora L\&PM, 2014.

\section{Sobre os autores}

\section{Fernanda Freitas Costa de Torres}

Pós-Doutorado concluído no Programa de Pós-Graduação em Design da Universidade de Brasília. Pesquisadora do RESTAURO - Núcleo de Pesquisa em Mobiliário Moderno Brasileiro. Suas investigações avançam em três linhas: Design e patrimônio cultural - Restauro de Mobiliário Moderno e Educação Patrimonial. Professora do Instituto Federal de Brasília.

ORCID. https://orcid.org/0000-0003-1730-1056

\section{Frederico Hudson Ferreira}

Professor ativo Permanente do Instituto Federal de Brasília, Coordenador do RESTAURO Núcleo de Pesquisa em Mobiliário Moderno Brasileiro. Doutor em Teoria e História da Arte no Instituto de Artes na Universidade de Brasília. Membro do Conselho do Patrimônio Cultural CONDEPAC/SECULT no Distrito Federal. ORCID. https://orcid.org/0000-0002-1793-4120 